\title{
A modified deep sclerectomy with or without external trabeculectomy: a comparative study
}

This article was published in the following Dove Press journal:

Clinical Ophthalmology

12 June 2010

Number of times this article has been viewed

\section{George Kitsos' \\ Miltiades Aspiotis' \\ Yannis Alamanos ${ }^{2}$ \\ Konstantinos Psilas' \\ 'Department of Ophthalmology, Medical School, University of loannina, Ioannina, Greece; ${ }^{2}$ Department of Hygiene and Epidemiology, Medical School, University of Patras, Patras, Greece}

Correspondence: George Kitsos

Department of Ophthalmology, University of loannina, School of Medicine, 45 I I0,

loannina, Greece

Tel +30 2651042504

Fax +302651049709

Email gkitsos@cc.uoi.gr
Purpose: To determine whether the removal of the inner wall of Schlemm's canal (external trabeculectomy) improves the effectiveness of a modified method of deep sclerectomy (DS), which we will call "reversed" deep sclerectomy (RDS).

Materials and method: We conducted a prospective study of two groups of patients. Group A included 22 eyes of 18 patients with open angle glaucoma (OAG) under maximum medical treatment, which underwent RDS - a modified method of performing DS - with the removal of the inner wall of Schlemm's canal (external trabeculectomy) and without using any implant. Group B included 20 eyes of 17 patients which had undergone RDS alone. Demographic and tonometric data of patients of Group A revealed no significant difference from data of patients in Group B. A mean follow up period for Group A was 22.8 months and for Group B was 23.4 months. The outcome of the operations was termed a total success when intraocular pressure (IOP) was $<21 \mathrm{mmHg}$ postoperatively, without additional treatment, relative success when IOP was $<21 \mathrm{mmHg}$ with additional treatment and a total failure when IOP $>21 \mathrm{mmHg}$ with medical treatment.

Results: Total success was achieved in $18 / 22$ eyes (81.8\%) for Group A and in $8 / 20$ eyes (40\%) for Group B $(P<0.05)$. Relative success was achieved in 22/22 $(100 \%)$ for Group A and in $17 / 20$ eyes $(85 \%)$ in Group B $(P=$ NS). Total failure occurred in $0 / 22$ eyes $(0 \%)$ in Group A and in 3/20 (15\%) eyes in Group B $(P=$ NS). The mean postoperative IOP in Group A was $13.5 \pm 2.8 \mathrm{mmHg}$ with a reduction of $12.4 \pm 4.6 \mathrm{mmHg}(48.1 \%)$ and in Group B mean postoperative IOP was $18 \pm 4.3 \mathrm{mmHg}$ with a reduction of $6.2 \pm 6.9(25.6 \%)(P<0.001)$. Mean drug reduction postoperatively was $3.2 \pm 0.9$ drugs in Group A and $1.7 \pm 1.2$ in Group B $(P<0.001)$.

Conclusion: In the follow up time during which the two groups were under study (12-36 months), the removal of the inner wall of Schlemm's canal while performing RDS proves an important factor in improving its effectiveness.

Keywords: modified deep sclerectomy, external trabeculectomy

\section{Introduction}

Deep sclerectomy (DS) with or without collagen implant ${ }^{1-9}$ is a non-penetrating, tunneling surgical procedure for the treatment of medically uncontrolled open-angle glaucoma (OAG). It was designed to lower the risk of classic trabeculectomy complications. ${ }^{10-12}$

Tissues in the angle of the anterior chamber are believed by most researchers to be responsible for the main aqueous outflow resistance in glaucoma. ${ }^{13-15}$ During classic DS, after the removal of the external layers of Schlemm's canal, its inner wall and the juxtacanalicular meshwork are left intact. Through acquired past experience and taking 
into consideration the modifications suggested, DS has been proven to be a reliable alternative to trabeculectomy. ${ }^{9,16-32}$ However a significant disadvantage to DS is its long learning curve. , $^{33-35}$

We applied a modified DS, called "reversed" deep sclerectomy (RDS). This RDS procedure did not remove additional tissue compared to classic DS. ${ }^{36}$ The idea of Zimmerman and colleagues ${ }^{37}$ to remove the inner wall of Schlemm's canal with the adjacent trabecular layers, but without the juxtacanalicular tissue (tissue that constitutes a site of great outflow resistance) during the procedure of nonperforating tunneling (external trabeculectomy) was a clever one. Most authors agree that external trabeculectomy significantly lowers intraocular pressure (IOP) and greatly improves outflow in protruding eyes of both pigs and humans. ${ }^{9,38,39}$

The aim of our study is to compare the postoperative results of RDS with external trabeculectomy to RDS alone (without external trabeculectomy) in patients with medically uncontrolled OAG, in order to determine whether the external trabeculectomy improves the effectiveness of RDS in IOP regulation.

\section{Materials and methods}

Group A includes 22 eyes of 18 patients with uncontrolled $\mathrm{OAG}$, despite receiving maximum tolerable medical treatment, which underwent RDS with the removal of the inner wall of Schlemm's canal and the external layers of the trabecular meshwork with external trabeculectomy. We excluded eyes with perforation of the anterior chamber during this procedure (RDS and external trabeculectomy).

Group B includes 20 eyes of 17 patients with uncontrolled $\mathrm{OAG}$, despite receiving maximum tolerable medical treatment, that have undergone RDS without the removal of the external layers of trabecular meshwork and the inner wall of Schlemm's canal (without external trabeculectomy). The selection of patients was made in such a way that demographic and tonometric preoperative data could be compared to that of group A (Table 1). Furthermore the selection was undertaken by an individual who was unaware of the postoperative course of the cases. All patients of both groups gave their consent after being informed of the procedures. We excluded eyes with perforation of the anterior chamber during the RDS.

The mean preoperative IOP in group A was $25.8 \pm$ $3.6 \mathrm{mmHg}$ and in group B $24.2 \pm 5.1 \mathrm{mmHg}$, a difference that is not statistically significant. The average number of preoperative antiglaucoma drugs for group A was $3.5 \pm 0.7$ and for group B it was $2.8 \pm 0.5$; the difference being statistically significant $(P<0.001)$. The average follow-up time was similar for both groups $(22.8 \pm 7.8$ months for group A and $23.4 \pm 8.9$ months for group B).

For all patients of both groups, uncontrolled OAG was defined as measurement of IOP $\geq 21 \mathrm{mmHg}$ and progression of optic neuropathy and visual field defects, despite maximum tolerable antiglaucoma therapy. The criteria for the diagnosis of OAG were according to the American Academy of Ophthalmology (Glaucoma). ${ }^{40}$

Excluded from the study were patients with acute primary glaucoma, secondary glaucoma, patients with previous eye surgery or laser trabeculoplasty as well as patients with myopia or hypermetropia greater than $3 \mathrm{D}$ or astigmatism more than $1 \mathrm{D}$ that could potentially affect our measurements. Patients with pseudo-exfoliation glaucoma were included in the study. Preoperative examination included best corrected visual acuity, slitlamp biomicroscopy, gonioscopy, Goldmann applanation tonometry, static perimetry using the Humphrey perimeter 24-2 (Humphrey Inc, San Leandro, California, USA), ultrasound pachymetry (Pacline; OPTICON 2000 SpA, Rome, Italy) and dilated pupil determination of cup/disc ratio. All patients of both groups were Greek Caucasian and had OAG of the same severity. Their central corneal thickness was with within the normal range (group A: $549.32 \pm 29.4 \mu \mathrm{m}$, group B: $550.24 \pm 26.2 \mu \mathrm{m}$ )

Table I Demographic data of 35 patients (42 eyes)

\begin{tabular}{|c|c|c|c|}
\hline & Group A & Group B & $P$ value \\
\hline Number of patients & 18 & 17 & \\
\hline Males/females & $10 / 8$ & $9 / 8$ & \\
\hline Age, years, mean (SD) & $68.3(7.7)$ & $71.7(7.1)$ & NS \\
\hline Number of eyes with open-angle glaucoma & 22 & 20 & \\
\hline Eyes with primary open-angle glaucoma & 12 & 12 & \\
\hline Eyes with pseudo-exfoliation glaucoma & $10(45.4 \%)$ & $8(40 \%)$ & \\
\hline IOP $(\mathrm{mmHg})$ (preoperatively), mean (SD) & $25.8(3.6)$ & $24.2(5.1)$ & NS \\
\hline Number of antiglaucoma drugs (preoperatively), mean (SD) & $3.5(0.7)$ & $2.8(0.5)$ & $<0.01$ \\
\hline Follow-up time (postoperatively), (range I2-36 months), mean (SD) & $22.8(7.8)$ & $23.4(8.9)$ & NS \\
\hline
\end{tabular}

Abbreviations: SD, standard deviation; IOP, Intraocular pressure. 
and their blood pressure was controlled (with or without drug administration).

Postoperatively patients were examined in the first ten days and again up to one month postoperatively, while further examinations on most patients were performed at the Glaucoma Department of the University Eye Clinic or by medical attendants at their area of residence. The examination included best corrected visual acuity, slitlamp biomicroscopy and Goldmann applanation tonometry. Visual fields were performed every 6 months or annually at the Glaucoma department of our clinic.

All the ophthalmologists at the follow-up examinations were blinded to the fact that these patients were study patients.

\section{"Reversed" deep sclerectomy}

DS without implant was applied in a modified manner. It is a classic DS where prior to the formation of a deep scleral petal, Schlemm's canal is opened. The operations in both groups were performed by the same surgeon (PK) using retrobulbar anesthesia. A 4-0 silk suture is placed onto the superior rectus muscle of the operated eye followed by a dissection at the limbus at the 10th and 2nd hour where there are no large penetrating vessels.

In greater detail, a scleral flap of $4 \times 5 \mathrm{~mm}$ is prepared between 10th and 2 nd hours. The preparation of the flap is then extended reaching $1 \mathrm{~mm}$ from the stroma of the cornea. With the aid of a thin diamond knife, we seek Schlemm's canal and perform a radial incision at the limbus where the sclera changes into the darker area of the trabeculum. A guide for locating Schlemm's canal is the horizontal white fibres of the scleral spur that lie at the borderline of the white sclera. Just anterior of these fibers lies Schlemm's canal from which after perforation aqueous humor wells up.

Following the location of Schlemm's canal, a radial incision is extended to the opposite side of the quadrangle, dividing it into two equal parts. The depth of the incision must not extend to the full thickness of the scleral stroma in order to avoid reaching the ciliary body.

Two parallel incisions are then made on both sides of the initial incision near the oblique sides of the quadrangle, extending towards the limbus only, so as to facilitate the preparation of the anterior part of the deep scleral flap.

At this point, we perforate the anterior chamber in order to cause hypotony and thus separate the inner and outer layer of Schlemm's canal. Using very thin Vannas scissors, we excise the outer layer of Schlemm's canal by inserting one leg of the scissors into the canal from the main opening, first on one and then on the other side.
With the aid of a triangular sponge, we detach the anterior segment of the scleral flap from the underlying trabeculum. The detachment is extended beyond Schwalbe Iine towards Descemet's membrane, which we reveal at an area of about $0.5-1 \mathrm{~mm} .^{2}$ With the aid of small scissors, we excise this anterior segment of the deep scleral stroma.

The posterior part of the deep scleral stroma is separated into two parts (petals), with the aid of a diamond knife, leaving a very thin layer of the sclera corresponding to the ciliary body. One petal is then prepared up to its middle, while the remainder is undermined in order to fold the latter inside. In the same manner we fold the other petal, too. Due to the folding of the two petals, a triangular endoscleral space is formed. Next, we suture the superficial scleral flap placing two 10-0 sutures at the corners of the quadrangle. A small quantity of viscoelastic fluid is placed under the superficial flap. The conjunctiva is sutured at the limbus using two $8-0$ sutures.

If, during the preparation of the anterior segment of the deep scleral flap (towards Descemet's membrane), a small perforation of the trabeculo - Descemet's membrane was to take place, without iris prolapse, the operation would be continued. If the perforation is greater and the iris prolapses, then a peripheral iridectomy may be performed to allow continuation of the case without converting it to a typical trabeculectomy.

\section{"Reversed" deep sclerectomy and external trabeculectomy}

After formation of the deep scleral flap in the manner described, with the aid of a thin $15^{\circ} \mathrm{knife}$, we separate, going towards the end of Schlemm's canal, the outer layers of the corneoscleral meshwork which includes the inner wall of the Schlemm's canal. Using a thin pincer Bonn, we peel the whole part of the inner wall of Schlemm's canal with the external layers of corneoscleral meshwork without perforating the anterior chamber. Then, using 10-0 nylon sutures, we suture the superficial scleral flap at the two corners. A small quantity of viscoelastic fluid is injected into the endoscleral space or parathalamus ${ }^{41,42}$ and finally an $8-0$ silk suture is placed on the conjunctiva at the limbus.

Postoperatively, patients from both groups were treated with a combination of corticosteroid and antibiotic eye drops; 1-2 three times daily for three weeks. After the first week, Tropicamide eye drops were added 1-2 drops three times daily.

During the postoperative follow-up examination, if an encapsulated bleb formed or if signs of fibrosis of the bleb were evident with a simultaneous elevation of IOP, 
we perform subconjunctival injections of 5-Fluorouracil (5-Fu) $(0.1 \mathrm{ml}$ of a $5-\mathrm{Fu} 50 \mathrm{mg} / \mathrm{ml}$ solution) once daily for 5 days.

The results of the operation were considered from us a "total success" if the IOP did not exceed $21 \mathrm{mmHg}$ without administration of glaucoma drugs or without 5-Fu subconjunctival injections. The procedure was consider a "relative success" if IOP was maintained below $21 \mathrm{mmHg}$ with the aid of glaucoma drugs or/and 5-Fu subconjunctival injections, and the procedure was considered a "total failure" if the IOP exceeded $21 \mathrm{mmHg}$ with drugs or/and 5-Fu subconjunctival injections.

\section{Statistical analysis}

Results were statistically compared with the aid of $\chi^{2}$-test for qualitative parameters and Student's t-test for quantitative parameters. Kaplan-Meier curves were calculated from the moment of operation until the last followup or until registering as a failure.

\section{Results}

In both Group A and Group B, cases were included only if there was no perforation of the anterior chamber. We excluded the eyes, of both groups, with perforation during the procedure. The average follow-up time was 22.8 months (standard deviation $[\mathrm{SD}]=7.8$ ) for group A and 23.4 months $(\mathrm{SD}=8.9)$ for group $\mathrm{B}$. In Table 2, we present the postoperative results of our study.

In Group A, "total success" was achieved in 18 out of 22 eyes $(81.8 \%)$ at the time of the last follow-up examination. The remaining 4 eyes achieved IOP $\leq 21 \mathrm{mmHg}$ with glaucoma therapy, and/or 5-Fu subconjunctival injections; so that "relative success" was $100 \%$. The mean postoperative IOP was $13.5 \pm 2.8 \mathrm{mmHg}$ with a mean reduction of $12.4 \pm 4.6 \mathrm{mmHg}$ (48\%). The mean number of glaucoma drugs used preoperatively was $3.5 \pm 0.7$ (Table 1), and was reduced to $0.2 \pm 0.5$ postoperatively (mean reduction in drugs
$3.2 \pm 0.9$ ). In 2 eyes 5 -Fu subconjunctival injections were performed in "relative success".

In Group B, out of 20 eyes, we achieved "total success" in 8 eyes (40\%) and "relative success" $(85 \%)$ in 9 eyes upon adding glaucoma drugs. In 3 eyes there was "total failure" and IOP was lowered only after performing trabeculectomy. The mean postoperative IOP was $18 \pm 4.3 \mathrm{mmHg}$ and mean reduction $6.2 \pm 6.9 \mathrm{mmHg}(25.6 \%)$. The average number of glaucoma drugs used preoperatively was $2.8 \pm 0.5$ (Table 1 ) which was reduced postoperatively to $1.1 \pm 1.2$ (mean reduction of $1.7 \pm 1.2$ ). In 4 eyes, $5 \mathrm{Fu}$ subconjunctival injections were performed in 3 eyes with "relative success" and in one eye with "total failure".

The progression of optic nerve damage and visual field defects were stable with regards to eyes of both groups with total or relative success at follow-up. Regarding bleb formation in both groups, bleb morphology was low and diffuse. We did not note enlarged blebs or complications regarding inflammation during the follow-up period.

In 3 eyes of group $\mathrm{B}$, during the first three days postoperatively, a relative shallowing of the anterior chamber with hypotony was observed, which was quickly reversed. Similarly, shallowing was noticed in 8 eyes of group A.

In Figure 1 and in Table 3, we present the conduct of the mean postoperative IOP and during the entire follow-up period for both groups comparatively.

In Figure 2, two Kaplan-Meier curves are shown. In the curve corresponding to RDS, the percentage of total and relative success in 36 months fell to $83 \%$, while in the curve corresponding to RDS and external trabeculectomy, the percentage still remains at $100 \%$. The two were compared with the testing of log-rank and the difference was statistically significant $(P=0.08)$.

\section{Discussion}

It has become accepted by most authors that the main aqueous outflow resistance is detected in the inner wall of

Table 2 Postoperative results (42 eyes of 35 patients)

\begin{tabular}{llll}
\hline & Group A (22 eyes) & Group B (20 eyes) & P value \\
\hline Total success & $18 / 22(81.8 \%)$ & $8 / 20(40 \%)$ & $<0.05$ \\
Relative success & $22 / 22(100 \%)$ & $17 / 20(85 \%)$ & $\mathrm{NS}$ \\
Total failure & $0 / 22(0 \%)$ & $3 / 20(15 \%)$ & $\mathrm{NS}$ \\
Postoperative IOP $(\mathrm{mmHg})$, mean (SD) & $13.5(2.8)$ & $18(4.3)$ & $<0.00 \mathrm{I}$ \\
IOP decrease (mmHg), mean (SD) & $12.4(4.6)(48.1 \%)$ & $6.2(6.9)(25.6 \%)$ & $<0.00 \mathrm{I}$ \\
Number of antiglaucoma drugs postoperatively, mean (SD) & $0.2(0.5)$ & $1.1(0.9)$ & $<0.00 \mathrm{I}$ \\
Decrease in number of antiglaucoma drugs, mean (SD) & $3.2(0.9)$ & $1.7(1.2)$ & $<0.00 \mathrm{I}$ \\
Use of 5-FU (number of eyes) & $2(9.1 \%)$ & $4(20 \%)$ & $<0.00 \mathrm{I}$ \\
\hline
\end{tabular}

Abbreviations: SD, standard deviation; IOP, Intraocular pressure; 5-FU, 5-Fluorouracil. 


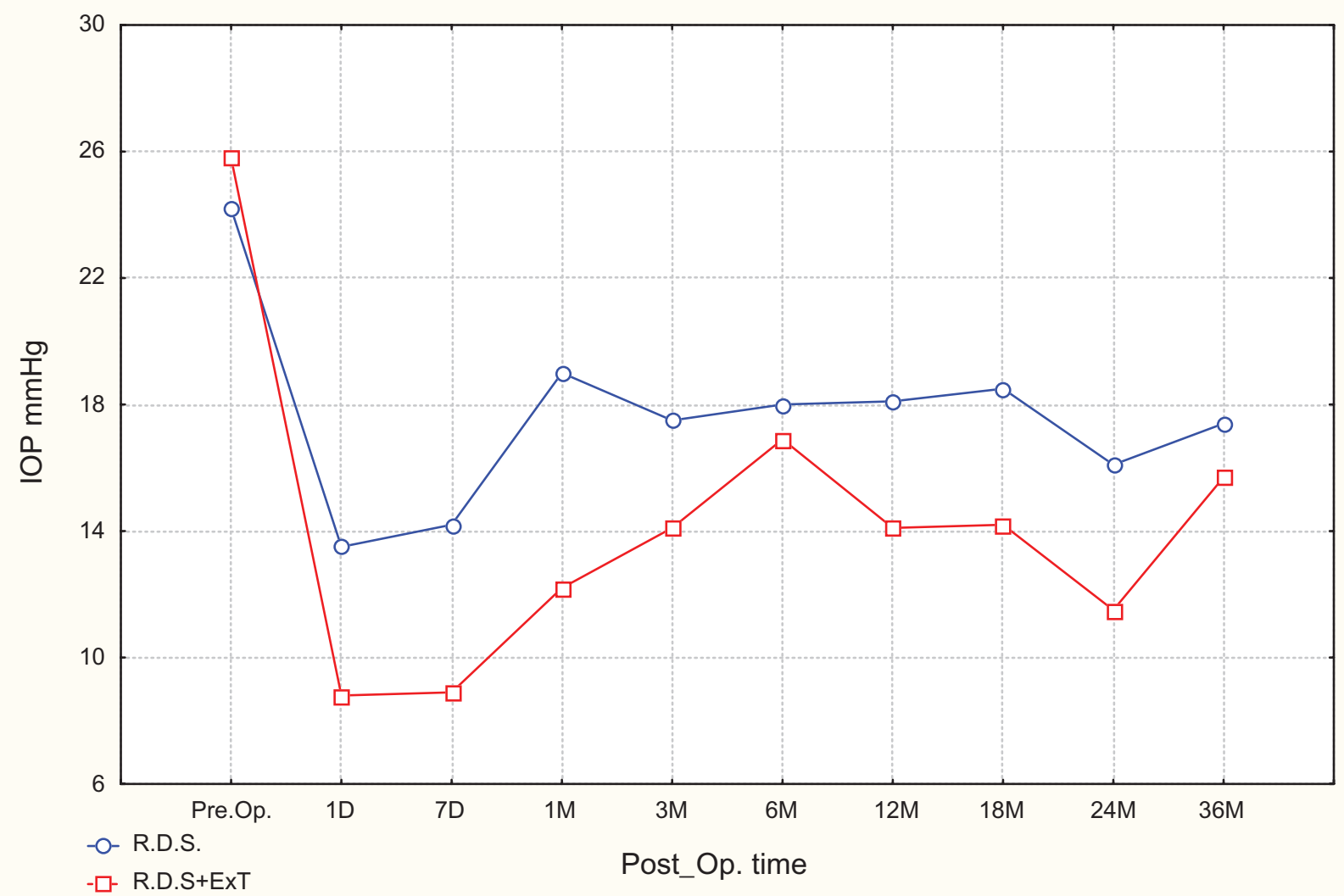

Figure I Mean IOP preoperatively and postoperatively in regular intervals during follow up in RDS and RDS and external trabeculectomy. Abbreviations: IOP, intraocular pressure; RDS, reversed deep sclerectomy.

Schlemm's canal and in the juxtacanalicular meshwork. ${ }^{13-15}$ The removal of a part of the trabeculum in a glaucoma operation would normally dramatically reduce the aqueous outflow resistance.

It was Zimmerman and colleagues ${ }^{37}$ who first developed the idea of removing the inner wall of Schlemm's canal with the external layers of the trabeculum, calling their method, non-penetrating trabeculectomy. However, this is in fact a deep sclerectomy with the removal of the inner wall of the Schlemm's canal and the outer part of the trabeculum (external trabeculectomy). ${ }^{9,35}$

Nowadays, many surgeons, combine DS with or without an implant with external trabeculectomy. ${ }^{2,3,6-9,17-25,43}$

Hamard and colleagues ${ }^{44}$ studying the histology of the inner wall of Schlemm's canal removed during the external trabeculectomy, proved that it contained the inner wall of Schlemm's canal rather than the juxtacanalicular meshwork and a very thin layer consisting of the external parts of the corneoscleral meshwork. The diaphragm therefore which separates the anterior chamber from the endoscleral space or parathalamus consists of a uveal trabecular meshwork and the largest part of the inner corneoscleral meshwork.

In one experimental study on protruding eyes of both pigs and humans, Rossier and colleagues ${ }^{38}$ observed that external trabeculectomy increased rather easily aqueous outflow. In our study, we compare the postoperative results of eyes in groups $\mathrm{A}$ and $\mathrm{B}$, consisting of cases of medically uncontrolled POAG. In group A consisting of 22 eyes of 18 patients, we applied RDS by removing the inner wall of Schlemm's canal (external trabeculectomy). In group B consisting of 20 eyes

Table 3 Mean (SD) of IOP preoperatively and postoperatively at regular intervals during follow-up

\begin{tabular}{|c|c|c|c|c|c|c|c|c|c|c|}
\hline & & \multicolumn{2}{|c|}{ IOP preoperative' } & \multicolumn{7}{|c|}{ IOP postoperative' } \\
\hline & & I day & 7 day & I day & 3 day & 6 day & I 2 day & 18 day & 24 day & 36 day \\
\hline Group A & $25.8(3.6)$ & $8.8(5.8)$ & $8.9(4.3)$ & $12.2(2.5)$ & $14 . \mid(3.1)$ & I6.9 (7.8) & I4.I (2.4) & I4.2 (2.9) & II.5 (2.0) & I $5.7(4.0)$ \\
\hline Group B & $24.2(5.1)$ & I3.5 (7.3) & $14.2(6.0)$ & $19.0(6.7)$ & $17.5(3.4)$ & $18.0(2.9)$ & |8.| (4.9) & $18.5(3.4)$ & 16.I (2.6) & $17.4(1.5)$ \\
\hline
\end{tabular}

Notes: 'The values are measured as $\mathrm{mmHg}$.

Abbreviations: SD, standard deviation; IOP, intraocular pressure. 

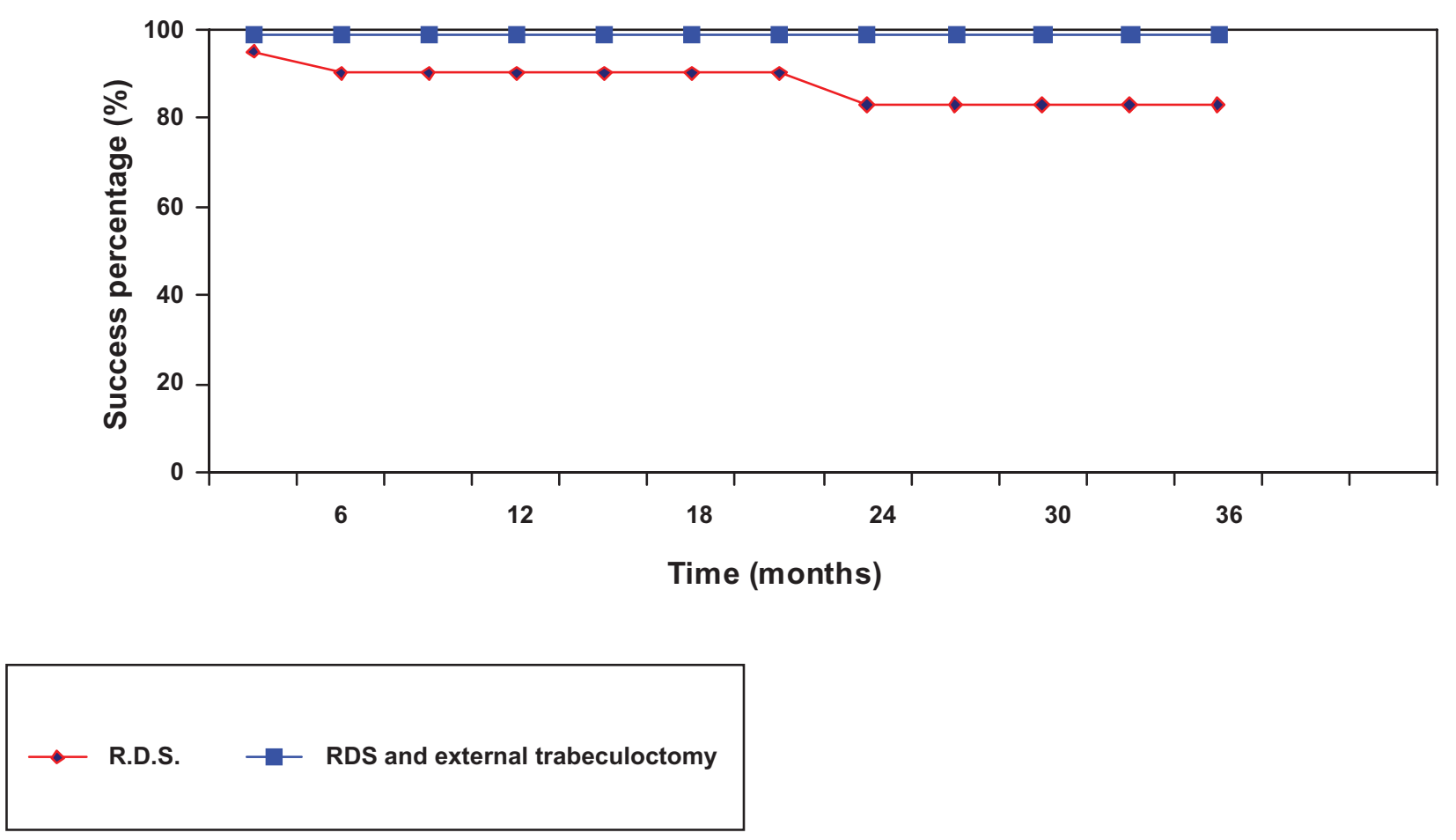

Figure 2 Kaplan-Meier curves for over time effectiveness of RDS and RDS and external trabeculectomy. Abbreviation: RDS, reversed deep sclerectomy.

of 17 patients, patients were operated using RDS method. As seen in Table 1, there is no statistically significant difference between groups A and B regarding the patients' age, the preoperative mean IOP and the average postoperative follow-up time. On the contrary, patients from group A used more glaucoma drugs preoperatively than patients from group $\mathrm{B}$ (3.5 \pm 0.7 compared to $2.8 \pm 0.5, P<0.01$ ). With regards to postoperative tonometric results (Tables 2 and 4), we observed a total success in Group A in $81.8 \%$ of cases, compared to $40 \%$ in group B $(P<0.05)$. Similarly, the mean postoperative IOP for group A was $13.5 \mathrm{mmHg}$ with a mean reduction of $12.4 \mathrm{mmHg}(48 \%)$ compared to $18 \pm 4.3 \mathrm{mmHg}$ and mean reduction of $6.2 \mathrm{mmHg}$ (25.6\%) in group B. Both these differences showed a significant statistical difference $(P<0,001)$. Even for group A, the average number of anti-glaucoma drugs used postoperatively is clearly less $(0.2 \pm 0.5$ as compared to $1.1 \pm 0.9, P<0.001)$. The postoperative statistically significant difference in the mean IOP and the percentage decrease in group $\mathrm{A}$ (as mentioned above) may well be explained by the fact that during an external trabeculectomy there is a greater increase of aqueous outflow through the remaining membrane to enter the parathalamus or endoscleral space. This occurs normally, because during the external trabeculectomy, together with the inner wall of Schlemm's canal and the meshwork, a limited number of external flaps from the corneoscleral trabeculum are removed.

Rossier and colleagues ${ }^{38}$ proved experimentally that the simple aqueous outflow of protruding human eyes is increased from $0.24 \pm 0.08 \mathrm{~mL} / \mathrm{min} / \mathrm{mmHg}$ to $6.33 \pm 6.67 \mathrm{~mL} / \mathrm{min} /$ $\mathrm{mmHg}$ after external trabeculectomy; an increase that is

Table 4 Tonometry data and antiglaucoma drug treatment (preoperatively and postoperatively)

\begin{tabular}{|c|c|c|c|c|}
\hline & Preoperative & & Postoperative & $P$ value \\
\hline \multicolumn{5}{|l|}{ Group A } \\
\hline $\mathrm{IOP}(\mathrm{mmHg})$, mean $(\mathrm{SD})$ & $25.8(3.6)$ & & $13.5(2.8)$ & $<0.001$ \\
\hline Decrease IOP (mmHg), mean (SD) & & $12.4(4.6)(48.1 \%)$ & & \\
\hline Number of antiglaucoma drugs, mean (SD) & $3.5(0.7)$ & & $0.2(0.5)$ & $<0.001$ \\
\hline \multicolumn{5}{|l|}{ Group B } \\
\hline IOP $(\mathrm{mmHg})$, mean $(\mathrm{SD})$ & $24.2(5.1)$ & & $18(4.3)$ & $<0.01$ \\
\hline Decrease IOP (mmHg), mean (SD) & & $6.2(6.9)(25.6 \%)$ & & \\
\hline Number of antiglaucoma drugs, mean (SD) & $2.8(0.5)$ & & I.I (0.9) & $<0.01$ \\
\hline
\end{tabular}

Abbreviations: SD, standard deviation; IOP, intraocular pressure. 
26 times greater. This increase can be explained by the fact that during external trabeculectomy, the diaphragm through the aqueous outflow consists only of the uveal meshwork and the largest inner part of the corneoscleral trabeculum meshwork.

From the comparison between two Kaplan-Meier curves, there is a difference between both methods which does not prove to be statistically significant $(P<0.08)$.

In relation to the postoperative IOP during the follow-up time (Figure 1 and Table 3), it is noted that cases that underwent external trabeculectomy show a greater hypotony in the first postoperative week when compared to cases having undergone RDS (average $8.9 \pm 4.3 \mathrm{mmHg}$ compared to $14.2 \pm 6.0$ ). The explanation for this observation may be that during an external trabeculectomy, the diaphragm which separates the anterior chamber from the parathalamus becomes much thinner.

It may be concluded from the cases which were studied for an average of 24 months (12-36 months), that RDS in combination with external trabeculectomy has better IOP regulation results than $\mathrm{RDS}$ alone.

\section{Disclosure}

The authors report no conflicts of interest relevant to this research. The authors alone are responsible for the content and writing of the paper.

\section{References}

1. Zimmerman TJ, Kooner KS, Ford VJ, et al. Trabeculectomy vs nonpenetrating trabeculectomy: a retrospective study of two procedures in phakic patients with glaucoma. Ophthalmic Surg. 1984;15: 734-740.

2. Fyodorov SN, Ioffe DI, Ronkina TI. Deep sclerectomy: technique and mechanism of a new glaucoma procedure. J Glaucoma. 1984; 6:281-283.

3. Kozlov VI, Bagrov SN, Anisimova SY, et al. [Deep sclerectomy with collagen] [Russian] Eye Microsurgery. 1990;3:44-46.

4. Mermoud A, Schnyder CC, Sickenberg M, Chiou AG, Hédiguer SE, Faggioni R. Comparison of deep sclerectomy with collagen implant and trabeculectomy in open-angle glaucoma. J Cataract Refract Surg. 1999;25:323-331

5. Karlen ME, Sanchez E, Schnyder CC, Sickenberg M, Mermoud A. Deep sclerectomy with collagen implant: medium term results. $\mathrm{Br} J$ Ophthalmol. 1999;83:6-11.

6. Demailly P, Jeanteur-Lunel MN, Berkani M, et al. [Non-penetrating deep sclerectomy combined with a collagen implant in primary open-angle glaucoma. Medium-term retrospective results] (French). J Fr Ophtalmol. 1996;19:659-666.

7. Sourdille P, Santiago PY, Villain F, et al. Reticulated hyaluronic acid implant in nonperforating trabecular surgery. J Cataract Refract Surg. 1999;25:332-339.

8. Kozobolis VP, Christodoulakis EV, Tzanakis N, Zacharopoulos I, Pallikaris IG. Primary deep sclerectomy versus primary deep sclerectomy with the use of mitomycin $\mathrm{C}$ in primary open-angle glaucoma. J Glaucoma. 2002;11:287-293.

9. Mendrinos E, Mermoud A, Shaarawy T. Nonpenetrating glaucoma surgery. Surv Ophthalmol. 2008;53:592-630.
10. Watson PG, Jakeman C, Ozturk M, Barnett MF, Barnett F, Khaw KT. The complications of trabeculectomy (a 20-year follow-up). Eye (London). 1990;4(Pt 3):425-438.

11. Kao SF, Lichter PR, Musch DC. Anterior chamber depth following filtration surgery. Ophthalmic Surg. 1989;20:332-336.

12. Stewart WC, Shields MB. Management of anterior chamber depth after trabeculectomy. Am J Ophthalmol. 1988;106:41-44.

13. Johnson MC, Kamm RD. The role of Schlemm's canal in aqueous outflow from the human eye. Invest Ophthalmol Vis Sci. 1983;24: 320-325.

14. Mäepea O, Bill A. Pressures in the juxtacanalicular tissue and Schlemm's canal in monkeys. Exp Eye Res. 1992;54:879-883.

15. Mäepea O, Bill A. The pressures in the episcleral veins, Schlemm's canal and the trabecular meshwork in monkeys: effects of changes in intraocular pressure. Exp Eye Res. 1989;49:645-663.

16. Stegmann R, Pienaar A, Miller D. Viscocanalostomy for open-angle glaucoma in black African patients. J Cataract Refract Surg. 1999; 25:316-322.

17. Cheng JW, Xi GL, Wei RL, Cai JP, Li Y. Efficacy and Tolerability of Nonpenetrating Filtering Surgery in the Treatment of Open-Angle Glaucoma: A Meta-Analysis. Ophthalmologica. 2009;224:138-146.

18. Mendrinos E, Mansouri K, Mermoud A, Shaarawy T. Long-term results of deep sclerectomy with collagen implant in exfoliative glaucoma. J Glaucoma. 2009;18:361-367.

19. Mansouri K, Tran HV, Ravinet E, Mermoud A. Comparing deep sclerectomy with collagen implant to the new method of very deep sclerectomy with collagen implant: a single-masked randomized controlled trial. J Glaucoma. 2010;19:24-30.

20. Chihara E, Okazaki K, Takahashi H, Shoji T, Adachi H, Hayashi K. Modified deep sclerectomy (D-lectomy MMC) for primary open-angle glaucoma: preliminary results. J Glaucoma. 2009;18:132-139.

21. Muñoz G. Nonstitch suprachoroidal technique for T-flux implantation in deep sclerectomy. J Glaucoma. 2009;18:262-264.

22. Godfrey DG, Fellman RL, Neelakantan A. Canal surgery in adult glaucomas. Curr Opin Ophthalmol. 2009;20:116-121.

23. Bissig A, Rivier D, Zaninetti M, Shaarawy T, Mermoud A, Roy S. Ten years follow-up after deep sclerectomy with collagen implant. J Glaucoma. 2008;17:680-686.

24. Galassi F, Giambene B. Deep sclerectomy with SkGel implant: 5-year results. J Glaucoma. 2008;17:52-56.

25. Leszczyński R, Gierek-Ciaciura S, Forminśka-Kapuścik M, MrukwaKominek E, Rokita-Wala I. Nonpenetrating very deep sclerectomy with reticulated hyaluronic acid implant in glaucoma treatment. Med Sci Monit. 2008;14:CR86-CR89.

26. Gianoli F, Schnyder CC, Bovey E, Mermoud A. Combined surgery for cataract and glaucoma: phacoemulsification and deep sclerectomy compared with phacoemulsification and trabeculectomy. J Cataract Refract Surg. 1999;25:340-346.

27. Chiselita D. Non-penetrating deep sclerectomy versus trabeculectomy in primary open-angle glaucoma surgery. Eye (London). 2001;15(Pt 2): 197-201.

28. El Sayyad F, Helal M, El-Kholify H, Khalil M, El-Maghraby A. Nonpenetrating deep sclerectomy versus trabeculectomy in bilateral primary open-angle glaucoma. Ophthalmology. 2000;107:1671-1674.

29. Cillino S, Di Pace F, Casuccio A, Cillino G, Lodato G. Deep sclerectomy versus trabeculectomy with low-dosage mitomycin $\mathrm{C}$ : four-year follow-up. Ophthalmologica. 2008;222:81-87.

30. Russo V, Scott IU, Stella A, et al. Nonpenetrating deep sclerectomy with reticulated hyaluronic acid implant versus punch trabeculectomy: a prospective clinical trial. Eur J Ophthalmol. 2008;18(5):751-757.

31. Carassa RG. Surgical alternative to trabeculectomy. Prog Brain Res. 2008;173:255-261.

32. Kotliar KE, Kozlova TV, Lanzl IM. Postoperative aqueous outflow in the human eye after glaucoma filtration surgery: biofluidmechanical considerations. Biomed Tech (Berlin). 2009;54:14-22.

33. Banchiero L, Demarie A, Belli L, Brogliatti B. Deep sclerectomy and viscocanalostomy : critical revision of the results obtained during the learning curve. Acta Ophthalmol Scand Suppl. 2002;236:64-66. 
34. Dahan E, Drusedau MU. Nonpenetrating filtration surgery for glaucoma: control by surgery only. J Cataract Refract Surg. 2000;26:695-701.

35. Baudouin C, Hamard P, Labbé A. [Surgical key points. Nonpenetrating sclerectomy]. J Fr Ophtalmol. 2007;30(5 Pt 2):3S52-7. Review. French.

36. Psilas K, Aspiotis M, Kitsos G, Eftaxias V, Psylla MK. The reversed deep sclerectomy in the treatment of the chronic open-angle glaucoma. XX Congress of the ESCRS; Nice, FRANCE, 2002. Abstract page 106.

37. Zimmerman TJ, Kooner KS, Ford VJ, et al. Effectiveness of nonpenetrating trabeculectomy in aphakic patients with glaucoma. Ophthalmic Surg. 1984;15:44-50.

38. Rossier A, Uffer S, Mermoud A. Aqueous dynamics in experimental ab externo trabeculectomy. Ophthalmic Res. 2000;32:165-171.

39. Guedes RA, Guedes VM. [Nonpenetrating deep sclerectomy in Brazil: a 3-year retrospective study] (French). J Fr Ophtalmol. 2005; 28:191-196.
40. Glaucoma: American Academy of Ophthalmology. The Eye MD Association. Lifelong Education for the Ophthalmologist, Section 10, 2008-2009; 1:3-16 and 4:85-121.

41. Lambrou N, Fronimopoulos J. [The role of the parathalamus in covered sclerectomy] [Article in German]. Klin Monbl Augenheilkd. 1984;184:259-260.

42. Lambrou N, Fronimopoulos J. [The significance of the scleral flap for the surgery of glaucoma (author's transl)] [Article in German]. Klin Monbl Augenheilkd. 1978;173:599-606.

43. Grehn F. [Surgery of primary open angle glaucoma] [Article in German]. Klin Monbl Augenheilkd. 2008;225:30-38.

44. Hamard P, Valtot F, Sourdille P, Bourles-Dagonet F, Baudouin C. Confocal microscopic examination of trabecular meshwork removed during ab externo trabeculectomy. Br J Ophthalmol. 2002;86: $1046-1052$.
Clinical Ophthalmology

\section{Publish your work in this journal}

Clinical Ophthalmology is an international, peer-reviewed journal covering all subspecialties within ophthalmology. Key topics include: Optometry; Visual science; Pharmacology and drug therapy in eye diseases; Basic Sciences; Primary and Secondary eye care; Patient Safety and Quality of Care Improvements. This journal is indexed on

\section{Dovepress}

PubMed Central and CAS, and is the official journal of The Society of Clinical Ophthalmology (SCO). The manuscript management system is completely online and includes a very quick and fair peer-review system, which is all easy to use. Visit http://www.dovepress.com/ testimonials.php to read real quotes from published authors. 